Eur. J. Clin. Chem. Clin. Biochem.

Vol. 32, 1994, pp. 305-311

(c) 1994 Walter de Gruyter \& Co.

Berlin · New York

\title{
Histochemical and Immunoelectron Microscopic Localization of Proteoglycans in Calcified Cartilage of Rat Epiphyseal Growth Plate
}

\author{
By H. Hagiwara ${ }^{1,2}$ and H.-J. Merker ${ }^{2}$ \\ 1 Department of Anatomy, Gunma University School of Medicine, 3-39-22, Showa-machi, Maebashi, Gunma 371, \\ Japan \\ 2 Institute of Toxicology and Prenatal Pharmacology, Free University of Berlin, Berlin, Germany
}

(Received July 28/September 6, 1993)

Dedicated to Prof. Dr. Dr. Helmut Greiling on the occasion of his 65th birthday

Summary: Localization and ultrastructure of proteoglycans during endochondral calcification or mineralization in the rat epiphyseal growth plate cartilage were investigated histochemically and by immunoelectron microscopy, using ruthenium hexammine trichloride and/or mouse monoclonal antibody (2-B-6) which recognizes chondroitin4-sulphated glycosaminoglycans. The gold particles of the second antibodies were distributed solitarily, lineally or in small clusters in calcified cartilage as well as in the surrounding non-calcified matrix. The labelled matrix glycosaminoglycans in the longitudinal septa increased from the proliferative to the upper hypertrophic zones and remained constant in calcified cartilage. After fixation with ruthenium hexammine trichloride, matrix proteoglycans precipitated and were observed as a reticular network of strands. Immunogold-labelled antibodies for the demonstration of the glycosaminoglycans were localized on these strands. Proteoglycans in calcified cartilage were observed as a network of fine-filamentous structures after ruthenium hexammine trichloride, showing their nonprecipitated native state. Immunostaining for chondroitin-4-sulphate indicated that there was no change in the concentration of glycosaminoglycans on the small calcified nodules in the areas where calcification was just beginning.

\section{Introduction}

Specific proteoglycạns and collagen type II are the two major components of the extracellular matrix of hyaline cartilage. Cartilage proteoglycans are mạcromolecules which consist of a core protein to which numerous chondroitin sulphate and a lesser number of keratan sulphate chains and a smaller number of $\mathrm{O}=$ linked and $\mathrm{N}$-linked oligosaccharides are covalently attached $(1-3)$. The cartilage proteoglycan monomers exist mostly in the form of aggregates through binding to hyaluronic acid. This attachment is stabilized by a link protein.

The growth plate cartilage is generally divided into the resting zone, the proliferative zone, the zone of maturation, and the hypertrophic zone (4). In the lower hy- pertrophic zone, the longitudinal septae begin to mineralize and this calcified cartilage is utilized as a scaffold for the formation of the metaphyseal spongiosa. While proteoglycans were formerly considered to be decreased or removed at sites of calcification (5-9), recent immunomorphological studies revealed the persistence of proteoglycans during endochondral calcification on the light microscopic level. Poole et al. (10) demonstrated with immunofluorescence microscopy that proteoglycan core proteins and link proteins are preserved without significant loss during mineralization of the longitudinal septa of cartilage matrix.

Using the immunoperoxidase method with specific monoclonal antibodies that recognize glycosaminogly- 
can epitopes, Byers et al. (11) found more recently that chondroitin-4-sulphate, chondroitin-6-sulphate and keratan sulphate persist in the calcified cartilage trabeculae.

On the ultrastructural level, however, the demonstration and observation of proteoglycans in calcified cartilage seem to be difficult. Employing the slam freezing and freeze substitution method, Arsenault et al. (12) revealed the proteoglycan network to be composed of thin and thick filaments in the cartilage matrix. However, these authors did not succeed in demonstrating such a network in calcified cartilage. Proteoglycans become detectable in the mineralized area after EGTA-chelation and precipitation with cationic dyes $(13,14)$. Shepard \& Mitchell (14) demonstrated rosette-like structures of proteoglycans at sites of mineralization in demineralized sections fixed in acridine-orange glutaraldehyde. As proteoglycans are considered to be structurally modified during demineralization, tissue preparations without demineralization are required in order to reveal the native state of proteoglycans in cartilage calcification.

The aim of our study was to examine the localization and ultrastructure of proteoglycans in calcified cartilage by histochemical and immunoelectron microscopic techniques. Ruthenium hexammine trichloride, which is a highly purified cationic dye of low molecular weight, high positive charge density and satisfactory diffusion properties (15), was utilized to precipitate and thus stabilize matrix proteoglycans. In order to avoid the loss and structural modifications of proteoglycans, cartilage tissues were not demineralized. As the predominant glycosaminoglycan in cartilage is chondroitin-4-sulphate (16), mouse monoclonal antibody 2-B-6, which specifically recognizes chondroitin-4-sulphate after digestion with chondroitinase $A B C$ (17), was used. In order to analyse changes in the amount of glycosaminoglycans associated with endochondral ossification, the number of gold particles in the different parts of longitudinal septa was further statistically investigated.

\section{Materials and Methods}

Female Wistar rats aged 4 to 6 weeks were used for this study. The animals were anaesthetized and killed with an overdose of ether. The proximal epiphyseal cartilage of femures was removed.

Tissue processing for immunoelectron microscopy

Epiphyseal cartilage tissues were cut into 0.5 to $1.0 \mathrm{~mm}$ slices and fixed in $30 \mathrm{~g} / \mathrm{l}$ paraformaldehyde $/ 1 \mathrm{~g} / \mathrm{l}$ glutaraldehyde in $0.1 \mathrm{~mol} / \mathrm{l}$ phosphate buffer ( $\mathrm{pH} \mathrm{7.4)}$ ) for $3 \mathrm{~h}$ at $4^{\circ} \mathrm{C}$. After a $30 \mathrm{~min}$ rinse in $0.1 \mathrm{~mol} / \mathrm{l}$ phosphate buffer containing $0.02 \mathrm{~mol} / \mathrm{l}$ glycine to block cell-bound free aldehyde groups, specimens were washed overnight in the same buffer. They were then dehydrated in a series of graded ethanols and finally embedded in LR-White (London Resin, Basingstoke, UK) at $50^{\circ} \mathrm{C}$ for $24 \mathrm{~h}$. Ultrathin sections were cut with an Ultracut $\mathrm{E}$ (Reichert) and picked up on nickel grids coated with Formvar.
Tissue processing with ruthenium hexammine trichloride for immunoelectron microscopy

Tissue preparation with ruthenium hexammine trichloride (Aldrich, Steinheim, Germany) was performed according to Hunziker et al. (15) with some modifications. Cartilage slices were fixed in $25 \mathrm{~g} / \mathrm{l}$ paraformaldehyde $/ 7 \mathrm{~g} / \mathrm{l}$ ruthenium hexammine trichloride in 0.05 $\mathrm{mol} / \mathrm{l}$ sodium cacodylate buffer for $2 \mathrm{~h}$. Following rinses in 0.05 $\mathrm{mol} / \mathrm{l}$ sodium cacodylate buffer 'Containing $7 \mathrm{~g} / 1$ ruthenium hexammine trichloride and $0.2 \mathrm{~mol} / \mathrm{l}$ sucrose, the specimens were dehydrated in a series of graded ethanols and finally embedded in LR-White or Epon.

\section{Immunoelectron microscopy for proteoglycan}

The mouse monoclonal antibody 2-B-6 (ICN Biochemicals, Mekkenheim, Germany) was used in this study. As this antibody reacts with $\Delta$-unsaturated disaccharides which are generated after chondroitinase $A B C$ digestion of chondroitin-4-sulphated glycosaminoglycans, immunostaining with this antibody requires treatment with the enzyme to produce the specific antigen.

The sections were initially digested with $1000 \mathrm{U} / 1$ chondroitinase ABC (Sigma, St. Louis, USA) in $0.1 \mathrm{~mol} / 1$ Tris acetate buffer (pH 7.6) for $1 \mathrm{~h}$. Phosphate-buffered saline containing $5 \mathrm{~g} / \mathrm{l}$ bovine serum albumin (Boehringer, Mannheim, Germany), $1 \mathrm{~g} / \mathrm{l}$ gelatin (Merck, Darmstadt, Germany), and $0.02 \mathrm{~mol} / 1 \mathrm{NaN}_{3}$ were utilized as incubation buffer for immunostaining. The grids were pretreated with incubation buffer supplemented with normal goat serum (volume fraction 0.05 ) for $20 \mathrm{~min}$, then incubated with mouse monoclonal antibody 2-B-6 diluted at 1:50 with incubation buffer at room temperature for $90 \mathrm{~min}$. They were washed 6 times with incubation buffer and incubated in $10 \mathrm{~nm}$ gold-labelled goat antimouse IgG (Fc) (Amersham Buchler, Braunschweig, Germany) diluted at 1:50 with incubation buffer at room temperature for 50 min. The sections were washed 6 times with phosphate-buffered saline, fixed with $10 \mathrm{~g} / \mathrm{l}$ glutaraldehyde in phosphate-buffered saline, and washed with distilled water. After staining with uranyl acetate/lead citrate with an Ultrastainer (LKB), the sections were examined under an electron microscope (Zeiss EM109, EM10). Grids for the control were incubated in normal mouse serum instead of the anti-glycosaminoglycan antibody. Before staining with uranyl acetate/lead citrate, some sections were contrasted with tannic acid and osmium gas. They were first stained with $1 \mathrm{~g} / \mathrm{l}$ tannic acid (Merck, Darmstadt; Germany) in $0.1 \mathrm{~mol} / \mathrm{l}$ sodium cacodylate buffer for $5 \mathrm{~min}$. After washing with distilled water, the grids were put in a Falcon $35 \mathrm{~mm}$ tissue culture plastic dish and treated with osmium tetroxide gas for $5 \mathrm{~min}$.

\section{Quantitative analysis of immunolabelling}

The intensity of immunogold labelling in the three different areas, (1) longitudinal septa of the proliferative zone, (2) longitudinal septa of the upper hypertrophic zone, and (3) calcified cartilage of the lower hypertrophic zone, was quantitatively compared. Nine to ten micrographs were taken per area at a magnification of 20000 and then magnified at 80000 . The number of gold particles per $1 \mu \mathrm{m}^{2}$ was calculated in each photograph and the density of gold particles was statistically analysed.

\section{Results}

Figure 1 shows a toluidine blue section of rat proximal epiphyseal growth plate cartilage of the femur. We could distinguish between the resting zone, proliferative zone, zone of maturation, and hypertrophic zone. Mineralizing matrix was observed in the lower hypertrophic zone. Due to fixation, i. e. precipitation of proteoglycans in the 


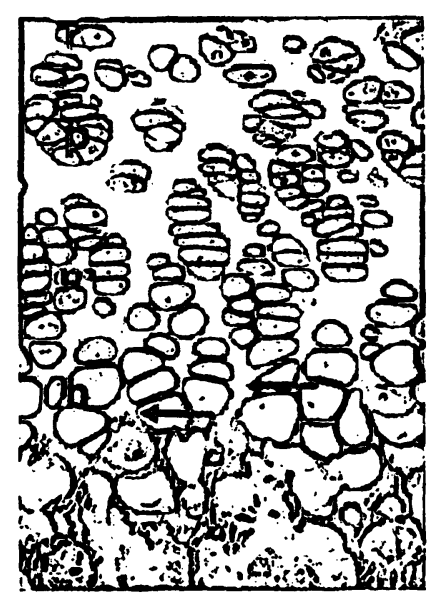

Fig. 1 Ruthenium hexammine trichloride-fixed, Epon-embedded material. One $\mu \mathrm{m}$ thick longitudinal section through the proximal epiphyseal growth plate of the femur. $r=$ resting zone; $p=$ proliferative zone; $m=$ zone of maturation; $h=$ hypertrophic zone with zone of onset of mineralization (arrow). Direct contact between cells and matrix. Magnification: 132

presence of ruthenium hexammine trichloride, chondrocytes were in direct contact with the matrix, i. e. leaching out of proteoglycans in the pericellular zone did not occur.

Immunoelectron microscopy revealed localization of chondroitin-4-sulphated glycosaminoglycans in calcified cartilage of the lower hypertrophic zone (fig. 2). Gold particles were arranged solitarily, lineally or in small clusters, as in the surrounding non-calcified matrix. After contrasting with $\mathrm{Ta} / \mathrm{O}$ s, matrix components were intensively stained (fig. 3). Cóllagen fibres and needleshaped apatite crystals were visible in the area of calcified cartilage.

Fixation in the presence of ruthenium hexammine trichloride led to precipitation and thus immobilization of the matrix proteoglycans (fig. 4). Proteoglycans in the non-calcified matrix appeared as a reticular structure composed of electron-dense strands. These proteoglycan strands became thinner near the calcified cartilage and continued to a fine filamentous network of proteoglycans in the calcified areas. After immunostaining of the cartilage fixed with ruthenium hexammine trichloride, gold particles were clearly located on these strands (fig. 5). Gold particles were also seen in calcified cartilage, but the fine filamentous network had almost completely disappeared due to digestion by chondroitinase $A B C$. Where mineralization was just beginning in the longitudinal septa of the hypertrophic zone, small nodules composed of a fine-filamentous network were observed after fixation with ruthenium hexammine trichloride (fig. 6). Focal concentrations of gold particles were not observed on these nodules after immunostaining (fig. 7).

The results of the quantitative analysis of immunogold labelling for chondroitin-4-sulphated glycosaminogly-

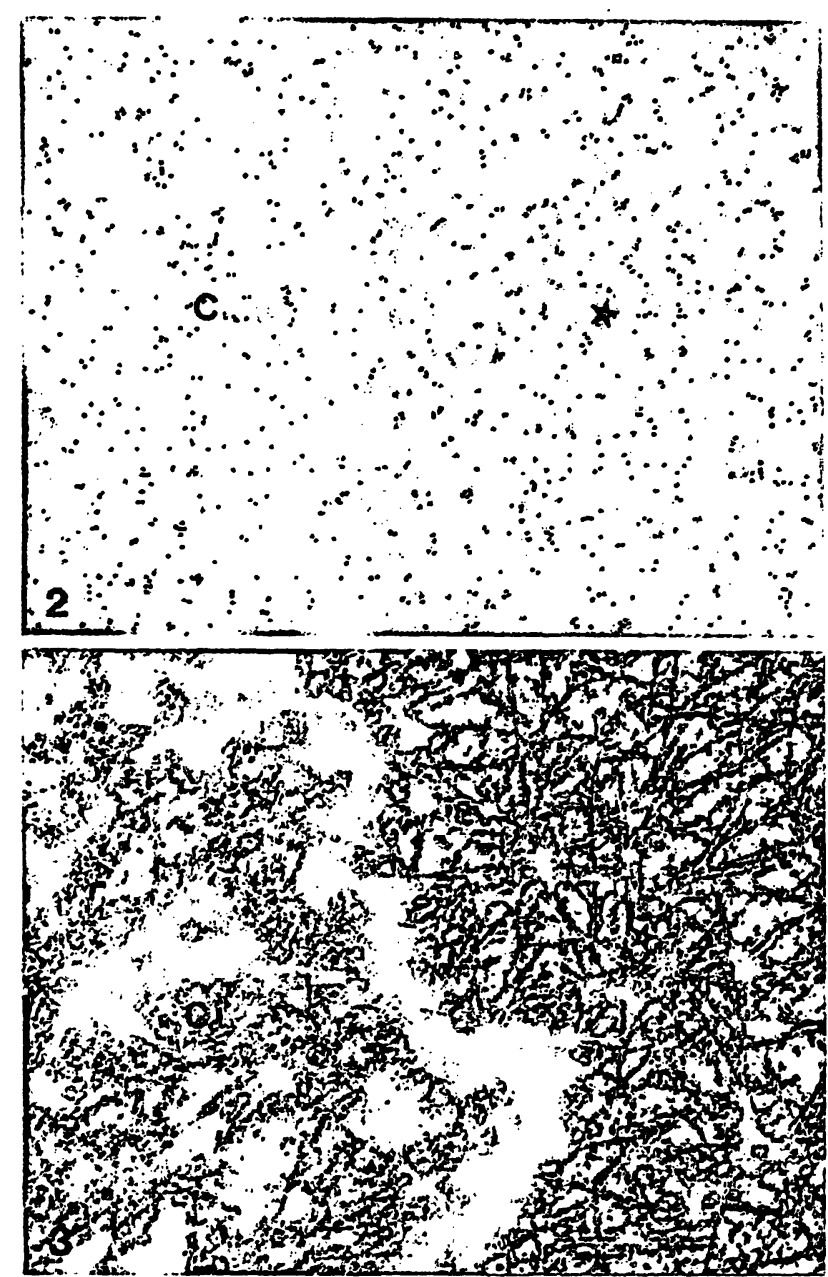

Fig. 2 Immunoelectron microscopic demonstration of chondroitin-4-sulphated glycosaminoglycans in a mineralized area (C) and in an area without apatite deposits $\left(^{*}\right)$ from the epiphyseal growth plate. LR-White embedding, with the usual uranyl acetate/lead citrate contrasting. Even distribution of gold-labelled second antibody. Magnification: 30600

Fig. 3 Immunoelectron microscopic demonstration of chondroitin-4-sulphated glycosaminoglycans in a mineralized area (C) and in an area without apatite deposits $\left(^{*}\right)$ from the epiphyseal growth plate. LR-White embedding, contrasting with tannic acid/OsO $\mathrm{S}_{4}$ Even distribution of gold-labelled second antibody. Magnification: 30600

can in the longitudinal septa of different zones are presented in table 1 . The data represent the numbers of gold particles per $\mu \mathrm{m}^{2}$. On both tissue preparations in the absence and presence of ruthenium hexammine trichloride, gold particles significantly increased from the proliferative zone to the upper hypertrophic zone, and they remained constant in calcified cartilage.

\section{Discussion}

In the present study, we demonstrated the localization of glycosaminoglycans in calcified cartilage with histochemical and immunomorphological techniques. Antigenicity of chondroitin-4-sulphated glycosaminoglycans was detected on the thick strands of proteoglycans after 
Tab. 1 Immunogold labelling intensities of chondroitin-4-sulphate following preparation in the absence and presence of ruthenium hexammine trichloride (gold particles per $\mu \mathrm{m}^{2} \pm \mathrm{SD}$ )

\begin{tabular}{|c|c|c|c|c|}
\hline Zone & $N$ & $\begin{array}{l}\text { Preparation } \\
\text { without ruthe- } \\
\text { nium hexammine } \\
\text { Irichloride }\end{array}$ & $\mathrm{N}$ & $\begin{array}{l}\text { Preparation } \\
\text { with ruthenium } \\
\text { hexammine tri- } \\
\text { chloride }\end{array}$ \\
\hline
\end{tabular}

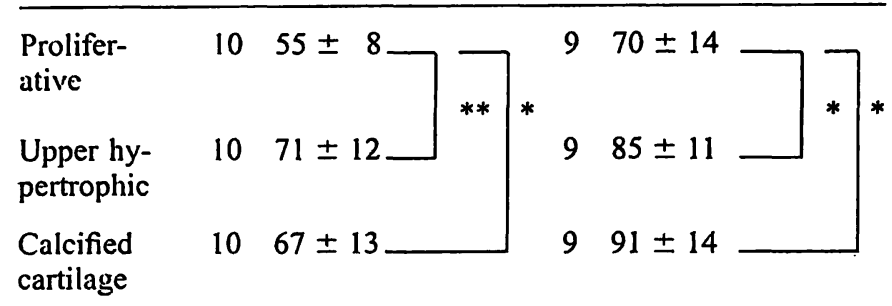

$* \mathrm{p}<0.05 ;{ }^{* *} \mathrm{p}<0.01$

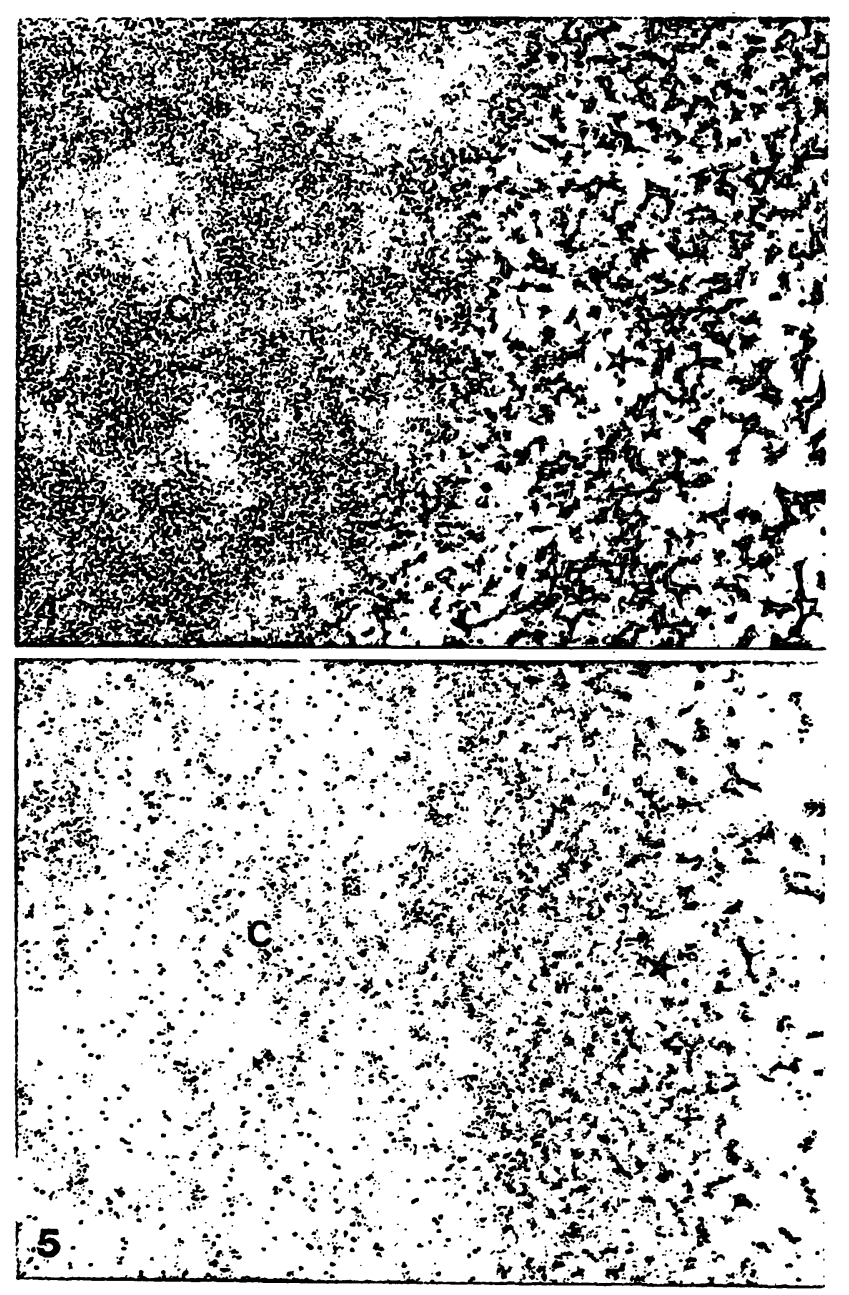

Fig. 4 Ruthenium hexammine trichloride-fixed, Epon-embedded material. Matrix from the area of hypertrophic cartilage with mineralized $(C)$ and unmineralized $(\star)$ areas. Distinct demonstration of bizarre-shaped, electron-dense proteoglycans in the unmineralized areas. The proteoglycans in the mineralized areas are smaller and fine-filamentous. Magnification: 30600

Fig. 5 Ruthenium hexammine trichloride-fixed, Epon-embedded material. Immunogold labelling of chondroitin-4-sulphạted glycosaminoglycans in mineralized (c) and unmineralized ( $\star$ ) areas. Mineralized areas do not show any proteoglycans, probably due to the action of the ABC-chondroitinase. Translucence is obviously intensified by leaching out of mineral after enzyme treatment. Even distribution of gold-labelled second antibody. Magnification:
30600 fixation in the presence of ruthenium hexammine trichloride.

Cationic dyes, such as ruthenium red $(7,18)$, lanthanum nitrate (19), alcian blue (20), toluidine blue $0(21)$, safranin 0 (22), ruthenium hexammine trichloride $(15,23)$, and acridine orange (14) precipitate matrix proteoglycans thus improving their electron microscopic demonstration. The ultrastructure of proteoglycans after fixation with cationic dyes is not homogeneous. They appear as round or polygonal granules, slender strands, in a ribbon-like configuration, or as multibranching structures, depending on the proteoglycan-precipitating capacity of the dyes used (24). Using cryotechnical tissue, the native state of matrix proteoglycans has recently been revealed to form a fine-filamentous network (12, $23,25,26)$. Although proteoglycans in the non-calcified matrix were seen as a reticular structure of condensed strands after ruthenium hexammine trichloride, proteoglycans in calcified cartilage were observed as a network of fine-filamentous structures, showing their non-precipitated state. Cartilage was not demineralized during tissue preparation. Proteoglycans in calcified cartilage are considered to be preserved in the intact state by ruthenium hexammine trichloride.

Immunoelectron microscopic demonstrations of proteoglycans in cartilage have been reported by several authors, using immunogold or immunoperoxidase methods $(24,27-29)$. These reports have successfully shown the localization of proteoglycans in the non-calcified cartilage matrix. They were, however, not concerned with calcified cartilage. We, however, investigated the immunolocalization of proteoglycans (chondroitin-4-sulphated glycosaminoglycans) in calcified cartilage at the ultrastructural level.

Cartilage calcification is a complex structural system in which, in addition to collagen type II and specific proteoglycans, various factors such as alkaline phosphatase (30), matrix vesicles $(3.1,36)$, the C-propeptide of collagen type II (32) (previously called chondrocalcin (33)), collagen type $X(34)$ and phospholipids (35) are involved. As isolated proteoglycans inhibit mineral crystal formation in vitro $(37,38)$, proteoglycans are considered to regulate the calcification process of cartilage. The changes in the amount and structure of proteoglycans during endochondral ossification have been intensively investigated. Previous biochemical studies noted that proteoglycans are lost from the matrix at the time of calcification $(8,9)$. As the volume occupied by matrix decreases in the hypertrophic zone (3), it is assumed that the content of proteoglycans is decreased when measured per weight of tissue. Using combined immunochemical/chemical-histomorphometric analyses, Alini et al. (40) revealed that the concentration of aggregating 


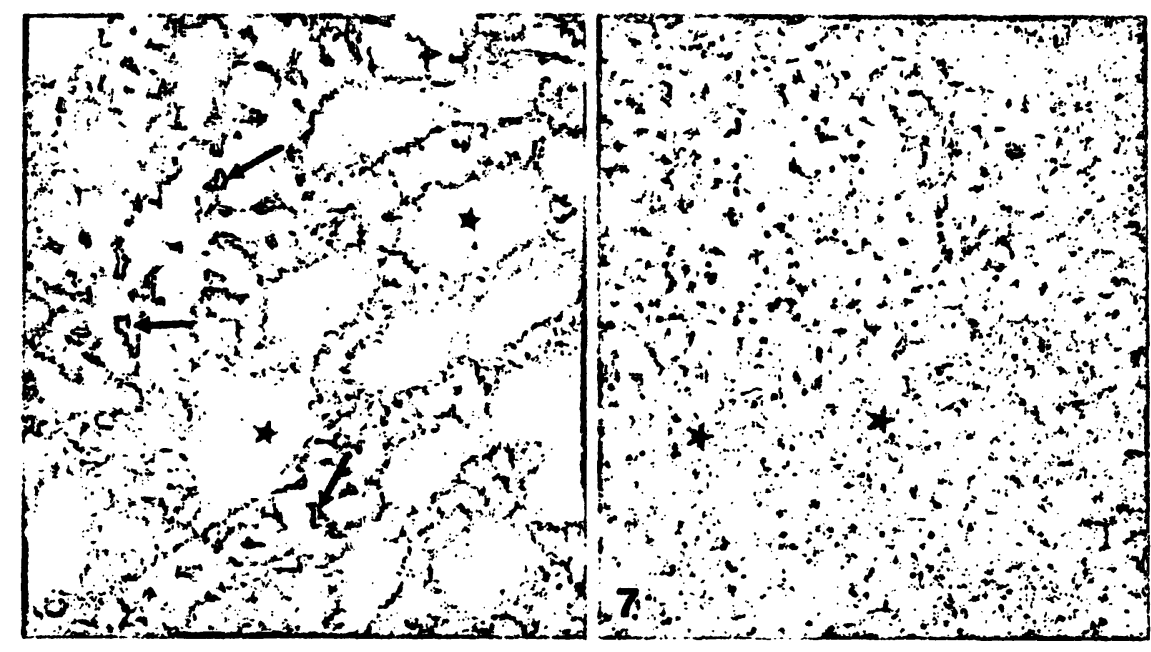

Fig. 6 Ruthenium hexammine trichloride-fixed, Epon-embedded material. Demonstration of large, bizarre-shaped proteoglycan structure (arrow) between mineralized plaques ( $\star$ ) of fine-filamentous material and apatite deposits in the zone of onset of mineralization in hypertrophic cartilage. Magnification: 42000

cartilage proteoglycans per unit matrix volume is highest in the lower hypertrophic zone of the growth plate of fetal bovine tibiae. On the light microscopic level the localization of proteoglycans in calcified cartilage has been successfully demonstrated, but it seems difficult to analyse the concentration of proteoglycans in the selected area with this method. As proteoglycans contain sulphur, elemental analysis has been introduced to measure the proteoglycan concentration in the matrix. On elemental analysis, the amount of proteoglycans increased from the proliferative to the calcifying zone (41), but considerably decreased with the onset of calcification $(41,42)$. Our statistical analysis of the number of gold particles against chondroitin-4-sulphate revealed that the in vitro concentration of matrix glycosaminoglycans increased from the proliferative to the upper hypertrophic zone and remained constant in calcified cartilage. These results support the immunochemical/chemical-histomorphometric analyses of proteoglycans by Alini et al. (40). The biochemical method might analyse the amount of proteoglycans more accurately than immunoelectron microscopy, but electron microscopic analysis can select the distinct area and investigate more locally the concentration of proteoglycans in the tissue. Our investigations are based on the assumption that the effects of enzyme treatment are identical in mineralized and unmineralized areas.

Shepard \& Mitchell (14) considered the rosette-like structure of proteoglycans, which were observed during mineralization after fixation with acridine orange, as indicating the selective increase of proteoglycan concentration. Poole et al. (4) estimated that a focal concentration of proteoglycan monomers occurs during the nucleation of calcification. Disaggregation and degradation
Fig. 7 Ruthenium hexammine trichloride-fixed, LR-White-embedded material. Even distribution of gold-labelled second antibody against chondroitin-4-sulphated glycosaminoglycans. Magnification: 30000

of cartilage proteoglycans during cartilage mineralization have also been observed in biochemical (43) and electron microscopic (44) investigations. As proteoglycan aggregates are more effective inhibitors of in vitro hydroxyapatite growth than proteoglycan monomers (38), the loss of aggregated proteoglycans with the calcification of cartilage seems to be reasonable. Proteoglycans in the calcified cartilage are observed as a network of fine filaments after ruthenium hexammine trichloride, rather resembling the pattern of native matrix proteoglycans demonstrated by cryotechniques. It is assumed that apatites are tightly embedded in the proteoglycans and fixed in the intact state without precipitation. The possibility exists that aggregated proteoglycans are broken during the development of the mineral, and that loss of aggregates is not a cause but a result of mineralization. Although it is evident that the density of glycosaminoglycans increased before mineralization, immunostaining revealed that there was no focal concentration of glycosaminoglycans in the small calcified nodules. Calcification occurs in the matrix where the concentration of proteoglycans is highest, but it is doubtful whether further concentration of glycosaminoglycans induces mineralization.

\section{Acknowledgement}

This work was supported by grants from the Deutsche Forschungsgemeinschaft awarded to Sfb 174. The authors wish to thank Mr. William-Henry Kiernan for his technical assistance and Mrs. Barbara Steyn for her help in preparing the manuscript. 


\section{References}

1. Hascall, V. C. \& Hascall, G. K. (1981) Proteoglycans. In: Cell Biology' of Extracellular Matrix (Hay, E. D., ed.) pp. 39-64, Plenum Press.

2. Doege, K., Sasaki, M., Horigan, E., Hassell, J. R. \& Yamada, Y. (1987) Complete primary structure of the rat cartilage proteoglycan core protein deduced from cDNA. J. Biol. Chem. 262, 17757-17767.

3. Carney, S. L. \& Muir, H. (1988) The structure and function of cartilage proteoglycans. Physiol. Rev. 68, 858-910.

4. Poole, A. R., Matsui, Y., Hinek, A. \& Lee, E. R. (1989) Cartilage macromolecules and the calcification of cartilage matrix. Anat. Rec. 224, 167-179.

5. Hirschman, A. \& Dziewiatkowski, D. D. (1966) Protein=polysaccharide loss during endochondral ossification: Immunochemical evidence. Science 154, 393-395.

6. Jibril, A. O. (1967) Proteolytic degradation of ossifying cartilage matrix and the removal of acid mucopolysaccharides prior to bone formation. Biochim. Biophys. Acta 136, 162-165.

7. Thyberg, J., Lohmander, S. \& Friberg, U. (1973) Electron microscopic demonstration of proteoglycans in guinea pig epiphyseal cartilage. J. Ultrastruct. Res. 45, 407-427.

8. Lohmander, S. \& Hjerpe, A. (1975) Proteoglycans of mineralizing rib and epiphyseal cartilage. Biochim. Biophys. Acta 404, 93-109.

9. Franzén, A., Heinegard, D., Reiland, S. \& Olsson, S.-E. (1982) Proteoglycans and calcification of cartilage in the femoral head epiphysis of the immature rat. J. Bone Joint Surg. 64-A, 558-566.

10. Poole, A. R., Pidoux, I. \& Rosenberg, L. (1982) Role of proteoglycans in endochondral ossification: Immunofluorescent localization of link protein and proteoglycan monomer in bovine fetal epiphyseal growth plate. J. Cell Biol. 92, 249-260.

11. Byers, S., Caterson, B., Hopwood, J. J. \& Foster, B. K. (1992) Immunolocation analysis of glycosaminoglycans in the human growth plate. J. Histochem. Cytochem. 40, 275-282.

12. Arsenault, A. L., Ottensmeyer, F. P. \& Heath, I. B. (1988) An electron microscopic and spectroscopic study of murine epiphyseal cartilage: Analysis of fine structure and matrix vesicles preserved by slam freezing and freeze substitution. J. Ultrastruct. Mol. Struct. Res. 98, 32-47.

13. Davis, W. L., Jones, R. G., Knight, J. P. \& Hagler, H. K. (1982) Cartilage calcification: An ultrastructural, histochemical, and analytical X-ray microscope study of the zone of calcification in the normal avian epiphyseal growth plate. J. Histochem. Cytochem. 30, 221-234.

14. Shepard, N. \& Mitchell, N. (1985) Ultrastructural modifications of proteoglycans coincident with mineralization in local regions of rat growth plate. J. Bone Joint Surg. 67-A, $455-464$.

15. Hunziker, E. B., Herrmann, W. \& Schenk, R. K. (1982) Improved cartilage fixation by ruthenium hexammine trichloride (RHT). J. Ultrastruct. Res. 81, 1-12.

16. Muir, H. \& Hardingham, T. E. (1975) Structure of Proteoglycans. In: Biochemistry of Carbohydrates, Vol. 5 (Whelan, W. J., ed.) pp. 153-221, Butterworth/University Park Press.

17. Caterson, B., Christner, J. E., Baker, J. R. \& Couchman, J. R. (1985) Production and characterization of monoclonal antibodies directed against connective tissue proteoglycans. Fed. Proc. 44, 386-393.

18. Luft, J. H. (1965) The fine structure of hyaline cartilage matrix following ruthenium red fixative and staining. J. Cell Biol. $27,61 \mathrm{~A}$.

19. Khan, T. A. \& Overton, J. (1970) Lanthanum staining of developing chick cartilage and reaggregation cartilage cells. J. Cell Biol. 44, 433-438.

20. Schofield, B. H., Williams, B. R. \& Doty, S. B. (1975) Alcian blue staining of cartilage for electron microscopy. Application of the critical electrolyte concentration principle. Histochem. J. 7, 139-149.

21. Shepard, N. \& Mitchell, N. (1976) Simultaneous localization . of proteoglycan by light and electron microscopy using tol- uidine blue $O$. A study of epiphyseal cartilage. J. Histochem. Cytochem. 24, 621-629.

22. Shepard, N. \& Mitchell, N. (1976) The localization of proteoglycan by light and electron microscopy using safranin $\mathrm{O}$. A study of epiphyseal cartilage. J. Ultrastruct. Res. 54, 451-460.

23. Hunziker, E. B. \& Schenk, R. K. (1984) Cartilage ultrastructure after high pressure freezing! freeze substitution, and low temperature embedding. II. Intercellular matrix ultrastructurepreservation of proteoglycans in their native state. J. Cell Biol. 98, 277-282.

24. Poole, A. R., Pidoux, I., Reiner, A. \& Rosenberg, L. (1982) An immunoelectron microscope study of the organization of proteoglycan monomer, link protein, and collagen in the matrix of articular cartilage. J. Cell Biol. 93, 921-93̄7.

25. Akisaka, T., Subita, G. P., Kawaguchi, H. \& Shigenaga, Y. (1987) Improved ultrastructural preservation of epiphyseal chondrocytes by the freeze-substitution method. Anat. Rec. 219, 347-355.

26. Takagi, M., Sasaki, T., Kagami, A. \& Komiyama, K. (1989) Ultrastructural demonstration of increased sulfated proteoglycans and calcium vesicles with chondrocyte cytoplasmic processes and matrix vesicles in rat growth plate cartilage. J. Histochem. Cytochem. 37, 1025=1033.

27. Takagi, M., Parmley, R. T. \& Denys, F. R. (1983) Ultrastructural cytochemistry and immunocytochemistry of proteoglycans associated with epiphyseal cartilage calcification. J. Histochem. Cytochem. 31, 1089-1100.

28. Ratcliffe, A., Fryer, P. R. \& Hardingham, T. E. (1984) The distribution of aggregating proteoglycans in articular cartilage: Comparison of quantitative immunoelectron microscopy with radioimmunoassay and biochemiçal analysis. J. Histochem. Cytochem. 32, 193-201.

29. Hunziker, E. B. \& Herrmann, W. (1987) In situ localization of cartilage extracellular matrix components by immunoelectron microscopy after cryotechnical tissue processing. J. Histochem. Cytochem. 35, 647-655.

30. Väänänen, H. K. (1980) Immunohistochemical localization of alkaline phosphatase in the chicken epiphyseal growth cartilage. Histochemistry 65, 143-148.

31. Bonucci, E. (1967) Fine structure of early cartilage calcification. J. Ultrastruct. Res. 20, 33-50.

32. van der Rest, M., Rosenberg, L. C., Olsen, B. R. \& Poole, A. $R$. (1986) Chondrocalcin is identical with the C-propeptide of type II procollagen. Biochem. J. 237, 923-925.

33. Poole, A. R., Pidoux, I., Reiner, A., Choi, H. \& Rosenberg, L. C. (1984) Association of an extracellular protein (chondrocalcin) with the calcification of cartilage in endochondral bone formation. J. Cell Biol. 98, 54-65.

34. Schmid, T. M. \& Linsenmayer, T. F. (1985) Immunohistochemical localization of short chain cartilage collagen (type $\mathrm{X}$ ) in avian tissues. J. Cell Biol. 100, 598-605.

35. Boskey, A. L., Posner, A. S., Lane, J. M., Goldberg, M. R. \& Cordella, D. M. (1980) Distribution of lipids associated with mineralization in the bovine epiphyseal growth plate. Arch. Biochem. Biophys. 199, 305-311.

36. Zimmermann, B., Wachtel, H. C. \& Noppe, C. (1991) Patterns of mineralization in vitro. Cell Tissue Res. 263, 483-493:

37. Blumenthal, N. C., Posner, A. S., Silverman, L. D. \& Rosenberg, L. C. (1979) Effect of proteoglycans on in vitro hydroxyapatite formation. Calcif. Tissue Int. 27, 75a-82.

38. Chen, C.-C., Boskey, A. L. \& Rosenberg, L. C. (1984) The inhibitory effect of cartilage proteoglycans on hydroxyapatite growth. Calcif. Tissue Int. 36, 285-290.

39. Hunziker, E. B., Schenk, R. T. \& Cruz-Orive, L.-M. (1987) Quantitation of chondrocyte performance in growth-plate cartilage during longitudinal bone growth. J. Bone Joint Surg. (Am.) 69, 162-173.

40. Alini, M., Matsui, Y., Dodge, G. R. \& Poole, A. R. (1992) The extracellular matrix of cartilage in the growth plate before and during calcification: Changes in composition and degradation of type II collagen. Calcif. Tissue Int. 50, 327-335. 
41. Hargest, T. E., Gay, C. V., Schraer, H. \& Wasserman, A. J. (1985) Vertical distribution of elements in cells and matrix of epiphyseal growth plate cartilage determined by quantitative electron probe analysis. J. Histochem. Cytochem. 33, 275286.

42. Mitchell, N., Shepard, N. \& Harrod, J. (1982) The measurement of proteoglycan in the mineralizing region of the rat growth plate. An electron microscopic and $X$-ray microanalytical study. J. Bone Joint Surg. 64-A, 32-38.

43. Campo, R. D. \& Romano, J. E. (1986) Changes in cartilage proteoglycans associated with calcification. Calcif. Tissue Int. $39,175-184$.
44. Buckwalter, J. A., Rosenberg, L. C. \& Ungar, R. (1987) Changes in proteoglycan aggregates during cartilage mineralization. Calcif. Tissue Int. 41, 228-236.

Prof. Dr. H.-J. Merker Institut für Toxikologie und Embryonal-Pharmakologie Freie Universität Berlin Garystraße 5 D-14195 Berlin Germany 


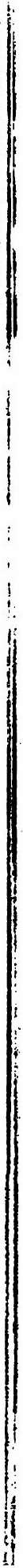

